\title{
Economic Impact Generated by the Public Open Space: Case Study of Klyde Warren Park
}

\author{
KOICHIRO AITANI \\ Texas A\&M University
}

Klyde Warren Park is Dallas's new town plaza which has literally and figuratively bridged the city's downtown cultural district with the burgeoning mixed-use neighborhoods to the north, reshaping the city and catalyzing economic development. The park brings Dallas-sites together in new ways, with dozens of free activities and amenities to offer every week, from concerts and lectures to games and fitness/yoga classes, all within a beautiful five-acre urban oasis. The park decks over the sunken Woodall Rodgers Freeway, which had been an imposing barrier between downtown and the densely populated Uptown neighborhood. Spurred by a study in $\mathbf{2 0 0 2}$ that confirmed the feasibility of a "deck park" over the freeway, leaders of the Dallas business community formed the non-profit Woodall Rodgers Park Foundation, which was responsible for the operations and maintenance of the new park with its operating hours from 6am to $11 \mathrm{pm}$. After ten years of planning, design, fundraising, and construction, Klyde Warren Park opened in the fall of 2012 and was immediately embraced by the community, cementing its place as a world-class urban park.

\section{INTRODUCTION}

"Editing Urban Design" is defined as the methodology of urban development with continuous partial developments and upgrades that maintain historical and community context. This discussion was focused on the "Urban Catalyst" methodology. The word 'Catalyst' is originally a chemistry term; however, in this research an "Urban Catalyst" is what stimulates a positive chain of effects within urban areas for regeneration.

Its characteristics are different from the conventional land development method such as the "Scrap \& Build" approach that is applied widely in urban regeneration. An Urban Catalyst is used to prompt a chain reaction and positively affect the surroundings beyond the limits of the developer's intentions or actions. It also discusses the characteristics and issues of the Urban Catalyst methodology including; how to find an input location and effect, transformation of the immediate context, and neighbors after the chain reactions. Four strategies of Urban Catalyst are also discussed briefly: Conservative Surgery, Minimal Intervention, Urban Acupuncture, Urban Infill.

In this paper, main objective is to see if Klyde Warren Park has a direct influence to the economic growth of Uptown and Downtown Districts of Dallas. Analysis on the market values of lots was conducted to see if there is any correlation to economic growth based on the presences of Klyde Warren Park.

\author{
SHOHEI YOSHINAGA \\ Texas A\&M University
}

\section{THE DALLAS GRID SYSTEM}

The Dallas grid system has evolved and adapted to the rapidly growing city ever since 1836 . Researching the Dallas grid included the history of master plans, square grids and the initial 45 degree angle pattern. Original settlements and the arrival of railroads and highways were also requisite data to collect for historic comparison. Aaron Benjamin's study of the Dallas grid system in 2013 were square grids, settlements, railroads, highways and master plans (figure 1). Dallas began the square grid in 1836 for John Grisby along the Trinity River. Peters Colony was created shortly after in 1841, which consisted of one mile square section grids by William S. Peters. In 1841 John Neely Bryan began 9x11 block areas along the Trinity River. Streets were planned on a 45 degree angle along the Trinity River following a Spanish tradition dating back to 1573. There are a few streets in Dallas facing directly north, but most streets follow the cardinal direction NW, SE. With this grid system each building is able to receive sunlight at some point in the day.

There were three original settlements in Dallas which are now monopolized by the expanded city. Beeman Homestead was the first settlement in 1842 and is now the Beeman family cemetery. The Oak Lawn neighborhood once used to be the Cedar Spring's settlement in 1843, belonging to John Cole. Hord's Ridge, owned by Judge W. H. Hord, was founded in 1845 and is now home to the Dallas Zoo parking lot. Railroads began arriving in 1872, and by 1881 Dallas became the hub for two major lines - the Dallas and Wichita Railroads. In 1910 there were ten separate rail lines running throughout the city. The first part of the Central Expressway arrived in 1947 and Woodall Rodgers Freeway was completed by 1983.

\section{METHODOLOGY}

In conducting this research, the area of uptown Dallas and downtown Dallas was divided each into three subsections, extending to one square mile around the center of Klyde Warren Park, aligned to the axis of Woodall Rodgers Freeway. Because the climate of the property values around the park to be a good indicator of the park's impact on the two areas, these values readily found on the Dallas County central appraisal district website are analyzed. In order to provide a holistic approach to the research, the property values for three years; 2008,2012 , and 2017, are examined, approximately covering the development of Klyde Warren Park from planning to present. The values both at these markers individually as well as the overall increase in property value as a percentage of the 2008 


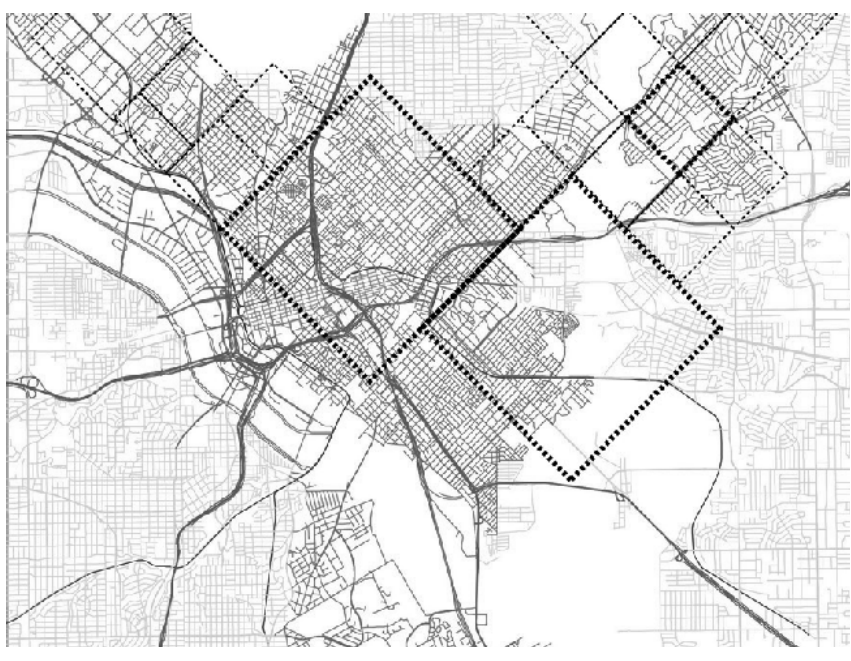

Figure 1: Urban Grid System of Dallas

property value, are examined. Because new development in the area could also have been spurred by the development of the new park district, the massive changes in value reflected by new developments are set to speak for themselves, rather than researching this separately.

To find and compile the property values for each district, the data was collected from the Dallas central appraisal district website to the "find property on map" link. Based on specific boundaries established for each research subsection, the properties and compiled the property values are divided into a spreadsheet. For large groups of small, closely related properties, such as a development of individually owned townhomes, the value of one property represent the value of the similar properties are set. Using the link that the account number of each parcel provides to that account's information, under "history," "total market value" under the "market value" section was selected. After compiling all of these values into the spreadsheet, another column was added with a formula which found the percentage increase between the 2008 value column and the 2017 value column. Finally, all of these values on four "density" style maps of one square mile area are plotted. For three property value maps, it was colored the properties a single color and used opacity to represent value on a scale from $\$ 0-\$ 100 M+$. For the value percentage increase map, the cold color was used to represent a decrease in value, warm color to represent an increase in value, and dark red to represent an increase greater than $100 \%$ of the 2008 value.

Additionally, the information that was gathered focused on the years 2008, 2012, and 2016. Since the park was built in 2012, by gathering information before and after the park was constructed to see if there was a pattern in the amount of tourist that visited the museums and theaters as well as the hotels.

\section{KLYDE WARREN PARK \& BRYANT PARK: PARK MANAGEMENT SYSTEM}

The park manage system of Klyde Warren Park was initiated by the support of the association of Bryant Park with the 5 revenue schemes as follows: 1) Business Improvement District (BID): Real State Assessment around the Park (on top of the property tax), 2) Sponsorship Income (like Sports Venue), 3) Event Rental Income, 4) Food \& Beverage Income, 5) Traditional Non-Profit Income: Annual Giving, Fund Raiser, Foundation (Grant Money). Etc.

\section{KLYDE WARREN PARK}

a. History: Klyde Warren Park is located in Dallas Texas and was opened in 2012. It was named after the Billionaire Kelcy Warren's son Klyde. The Design Team consisted of, the office of James Burnett who was in charge of the Landscape design, Jacobs Engineering Group was the Structural Engineers and Bjerke Management Solutions was in charge of the overall design and construction of this project. Funding came through private and public funds. The city of Dallas provided around 20 million in bonds funds while TxDOT gave 20 million in highway funds. 50 million dollars came through private donations (figure 2).

B. Circulation: Klyde Warren Park is approximately 5.2 acres. Since it fits directly above a highway, the park can fit 10,000 people comfortably with around 4 feet of square feet per person. The vehicle circulation around the park is pretty normal, there are two main streets that run on the longest sides of the park, and then two main streets that run on the ends of the park When the park was made the design team decided to shut down on of the through streets. They did this to allow the park to be connected within itself. There is one through street that splits the park up into two sections.

c. Spaces within the Park: The spaces within the park have the main lawn space centered in the middle of the park, giving an open setting where people can have picnics, and many other outdoor activities. There are also spaces for smaller kids and water areas, a music pavilion, a commons area and even a restaurant. All of these different areas attract a large target audience and are why there are over 1 million visitors a year here.

d.Events: Klyde Warren Park has a ton of events throughout the year, whether it be for a holiday, fitness class, food, or just getting people together to have a great time. In the Spring, there are events like the Spring Fling which is just a massive spring party and festival. There is a Spring Concert series that runs from March 18th through April 27th. Food trucks are always a great reason to get outside and explore the city as well as going to weekly workout and yoga classes. In the evenings and night hours Movies in the park goes on throughout the month of May. All of these are great ways to get the family active and outside in the great city of Dallas. In the summer 


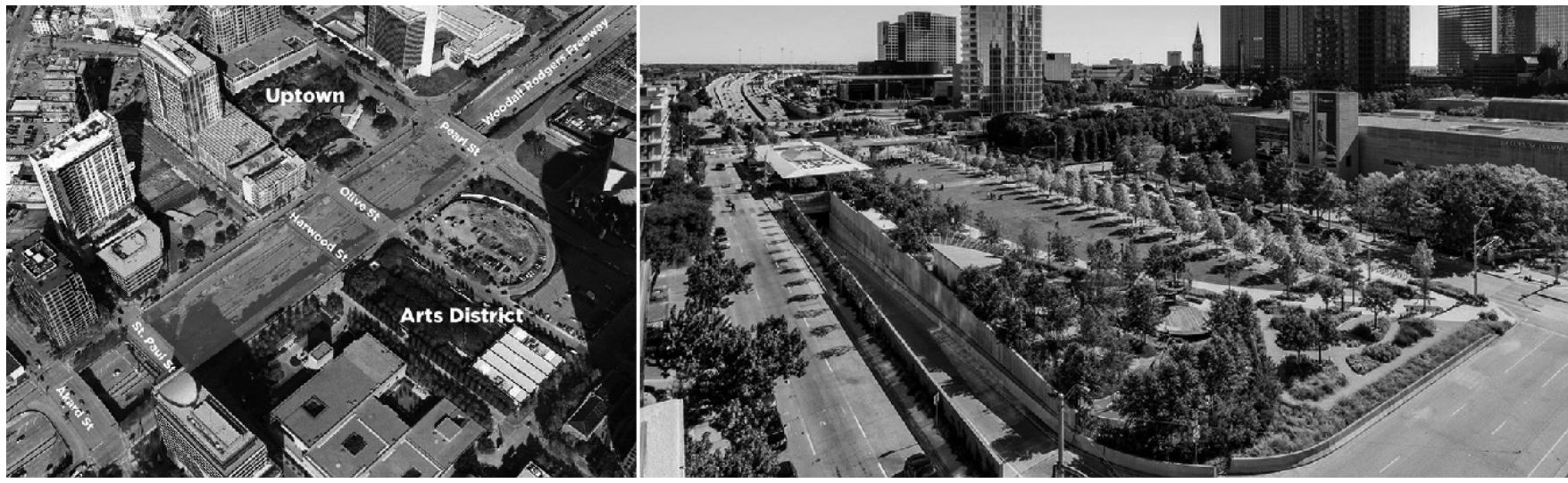

Figure 2: Klyde Warren Park before the construction (left), and after its construction (right) Image Source @ OJB Landscape Architecture

Klyde Warren Park has a lot of the same kind of events and activities as it does in the spring but there are events for the fourth of July and also Book clubs for kids to come and learn how to read with their friends. In the fall and winter times of the year, Klyde has a new kind of event going on in September called Park and Palate which is a fancy food and wine tasting event for the public. In the winter time the events are all about the holidays. Klyde even has an ice skating rink out for a period of time in the winter for anyone who wants to take on the challenge (figures 3 and 4).

\section{BRYANT PARK, NEW YORK}

a. History: Bryant Park, located in Manhattan, New York opened in 1874 originally used for military purposes but didn't have a great reputation. In the 80 's the park was taken over by the Bryant Park Restoration and began redevelop the park into a world-renowned park. The design team to redevelop Bryant Park was Daniel Biederman and Andrew Heiskall who successfully transformed the park. Funding originally was supported by the Rockefeller center. It then became funded by assessments on property \& revenue generated by park. The park does not accept any public funds and usually takes around 7 million dollars a year to keep the park running.

B. Circulation: Bryant Park is quite a bit larger than Klyde Warren Park being 9.6 acres. The vehicle circulation around the park is pretty normal with major roads lining each side of the park. The pedestrian circulation is laid out with a grid system, with wider walkways for larger amounts of pedestrian traffic while having smaller walkways for people wanting to go into different areas within the park that connect to these main walkways.

c. Spaces within the Park: The layout of the park is unique. There is a large great lawn in the center of the park, this area can be used for workout classes, picnics, etc. It is an open space that is very versatile for the city. There are also areas on the outer corners where people have access to the subway system, and bathrooms. Almost half of the park is taken up by the New York public library, this is a great space to have in the park because it is another attraction that gets people to the park and outside in the lawn to relax. Bryant Park also has four different areas around the park where food is available, there is a grille, a café, and then 2 different food kiosks where snacks and other types of food are available. In the center of the park on the edge of the great lawn there is a stage where concerts are held and different live performances take place.

d.Events: The events that occur at Bryant Park contribute to the overall success of the park's revenue and because of this there are countless events throughout the year. There are dozens of events that happen daily, some of these activities happen year around while others only happen on occasion. The continuous activities that occur daily include: chess, juggling, exercise activities, art carts, dancing, and story times. These events are free to the public, but some may have a maximum capacity for registration. One way to look at the events is by season since the weather and holidays bring about different types of activities. During the spring there are many activities ranging from athletics to educational. We see the most activity during the summer with many events going all through the day including Pilates, dancing, movie nights, and musical chairs. Holidays begin in the fall so we begin to see themed events for the Halloween season. The winter is a very popular time since this is when New York receives its cold weather and the ice skating rink open to the public. These events play a major part in New York's society and culture.

\section{HOTELS, MUSEUMS \& THEATERS NEAR KLYDE WARREN PARK}

To conduct the research information was collected through emails, phone calls, and websites. For the Museums and Theaters, more information was readily available, and for the hotels it was harder to find for its security reason. The only museum that had that information available online was The Dallas Museum of Art (DMA). The DMA is one of the largest museums in Dallas, with collections of more than 24,000 objects dating back almost 5,000 years. For that reason they have all their annual reports online for the public to see. The 


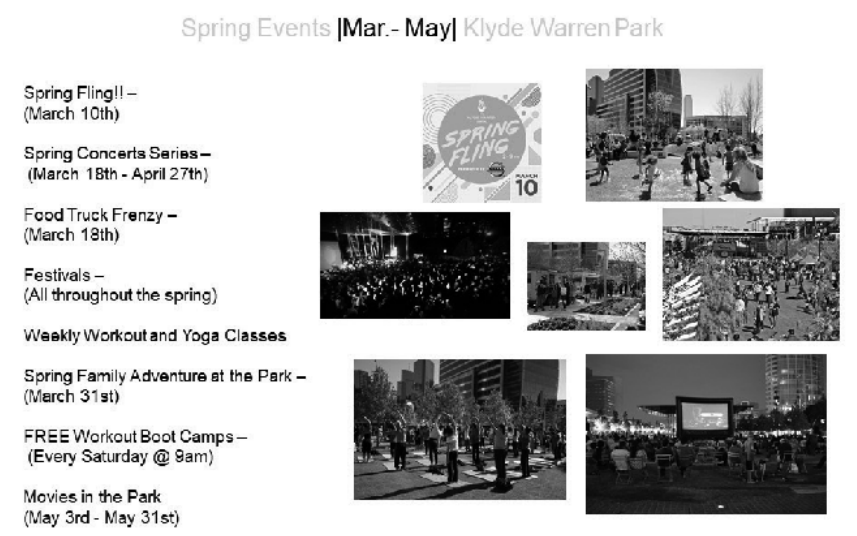

Fall Events |Sep.- Nov.| Klyde Warren Park

Park \& Palate -
(September 25th-26th)
Decks in the Park -
(October 29th)
Fall Social Events for Young Professionals-
(September 28th)
Halloween Parties and Festivals
(November 1st)
Bundt Day @ the Park
(Nothing Bundt Cakes)
(November 15th)
Workout Classes
Food Trucks

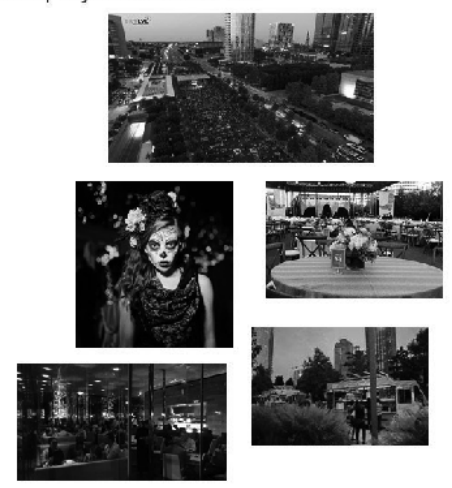

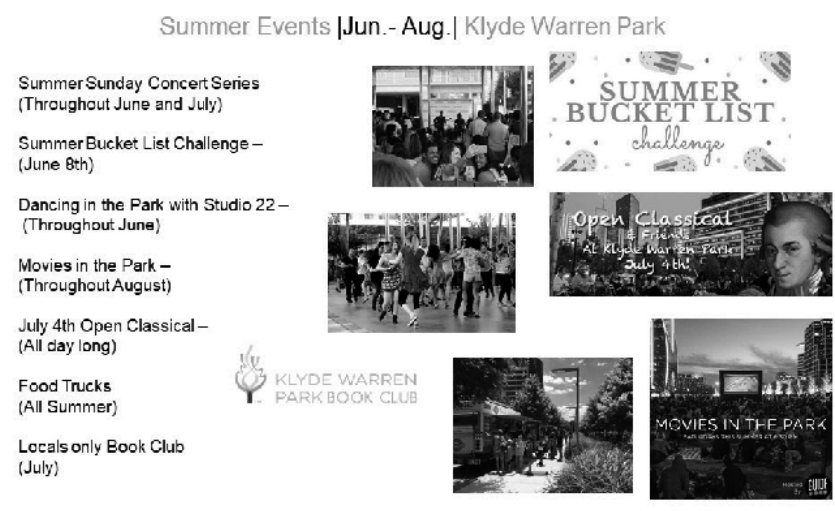

Winter Events |Dec.- Feb.| Klyde Warren Park

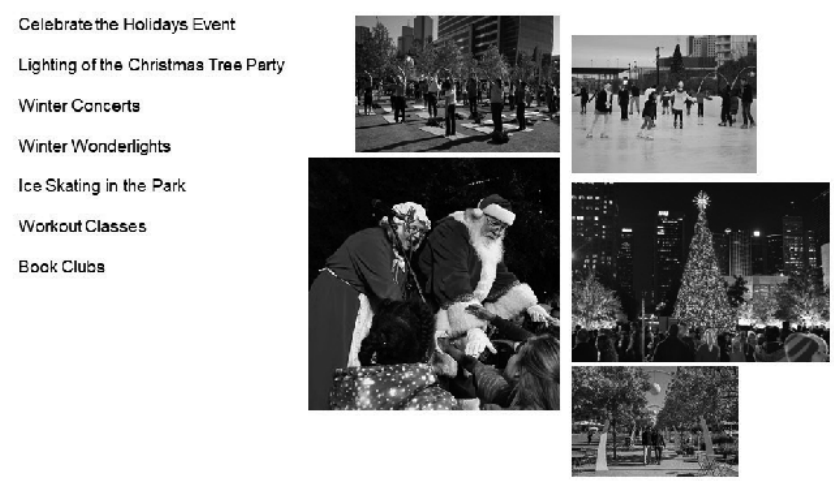

Figure 3: Event held at Klyde Warren Park (Spring, Summer, Fall \& Winter)

AT\&T Performing Art Center didn't have annual reports for each individual year, but it did have an overall annual report where it states how many visitors they have had since it opened in 2009. The Sixth Floor Museum exhibits the life, time, death, and legacy of John F. Kennedy and is located in exact location where Lee Oswald shot the President.

Analysis for the hotels in Uptown and in Downtown are concluded that the more expensive 4 to 5 -star hotels were in Uptown, while the 4 stars and below were in Downtown.

\section{POPULATION INCREASE}

This research provided with information about the population in uptown and downtown Dallas in different years before and after Klyde Warren Park was built. In 1990, the population in uptown Dallas was 4,809 while in downtown Dallas it was 3,444 . In 2000, the populations of uptown and downtown Dallas were 8,596 and 2,198 respectively. Ten years later, the population of uptown Dallas was 13,070 , while downtown Dallas had a population of 6,069. Klyde Warren Park was completed in 2012. The populations of uptown and downtown Dallas in 2013 were 16,920 and 6,742 respectively. In 2014 the population of uptown Dallas was 17,684 and downtown Dallas had a population of 7,298 . The population is continuing to rise since then in Dallas as a whole. The population also fluctuates from day to night time depending on commuters. There are about 150,000 commuters out of Dallas and about 700,000 that live in Dallas (not working). There are about 900,000 people that work and live in Dallas. There are about $1,400,000$ that commute to Dallas. The average age of the Dallas population is 29 years old for native born and 39 years old for foreign born. The number of households was 14,059 in 2015 which is a change of $+16.8 \%$ in the last five years (figure 5 ).

\section{DISCUSSION}

Although the results of this research cannot be directly conclusive to the theory that Klyde Warren Park increased all of the property values in the surrounding areas, it is very apparent that the park has had an overall productive impact on both uptown and downtown Dallas. A considerable amount of the properties that were found to decrease after the park are due to the fact that the property is being remodeled, rebuilt, or torn down to eventually enhance the previous property. Most of those remodels wouldn't be taking place if the park wasn't present. The park also did an impeccable job of connecting downtown and uptown so they feel more cohesive (figure 6). 


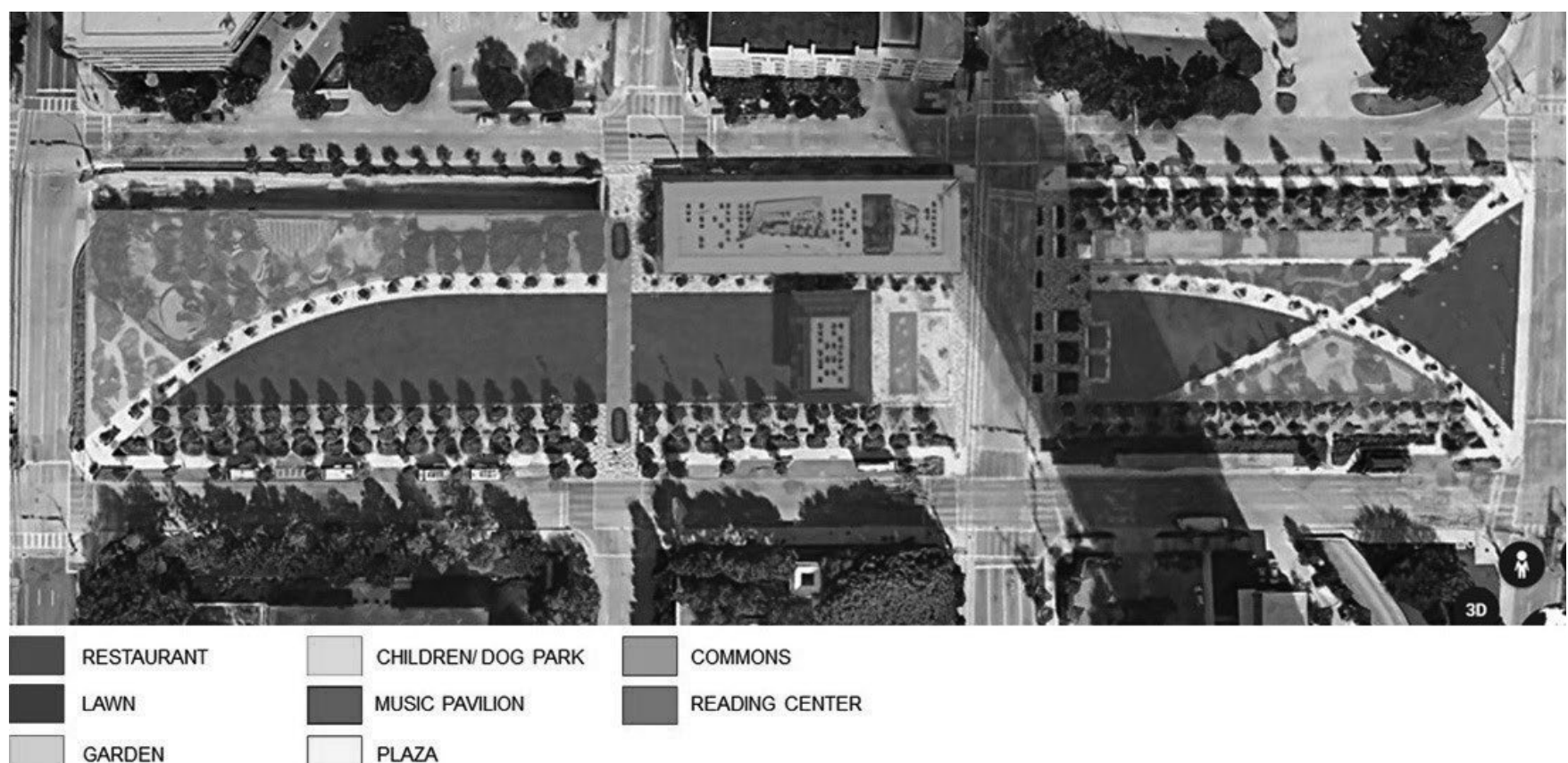

Figure 4: Spaces within Klyde Warren Park
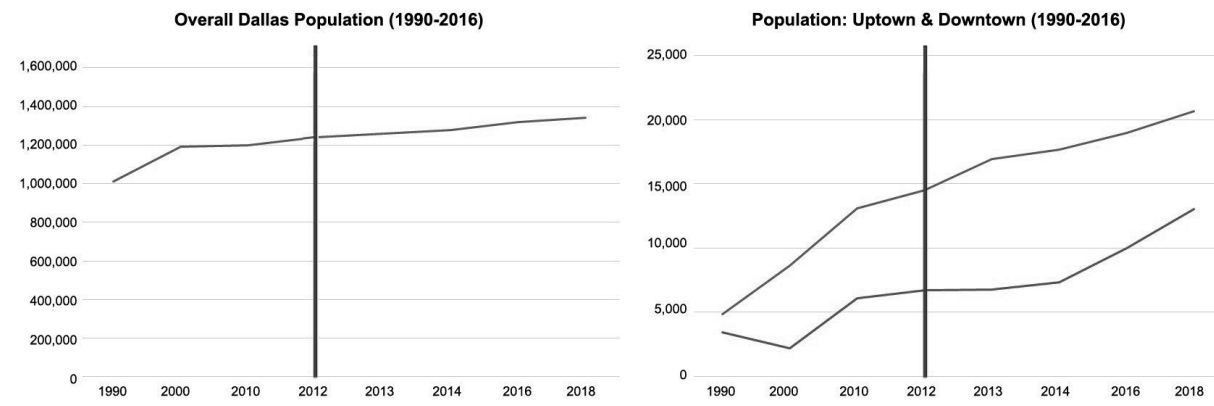

Figure 5: Population growth of Dallas (Left: 1990-2016), Population growth of Uptown Dallas and Downtown Dallas (Right: 1990-2016)

Figure 6: Key Buildings of Dallas (Left), and Market value growth of Dallas (Right:2012 - 2017)
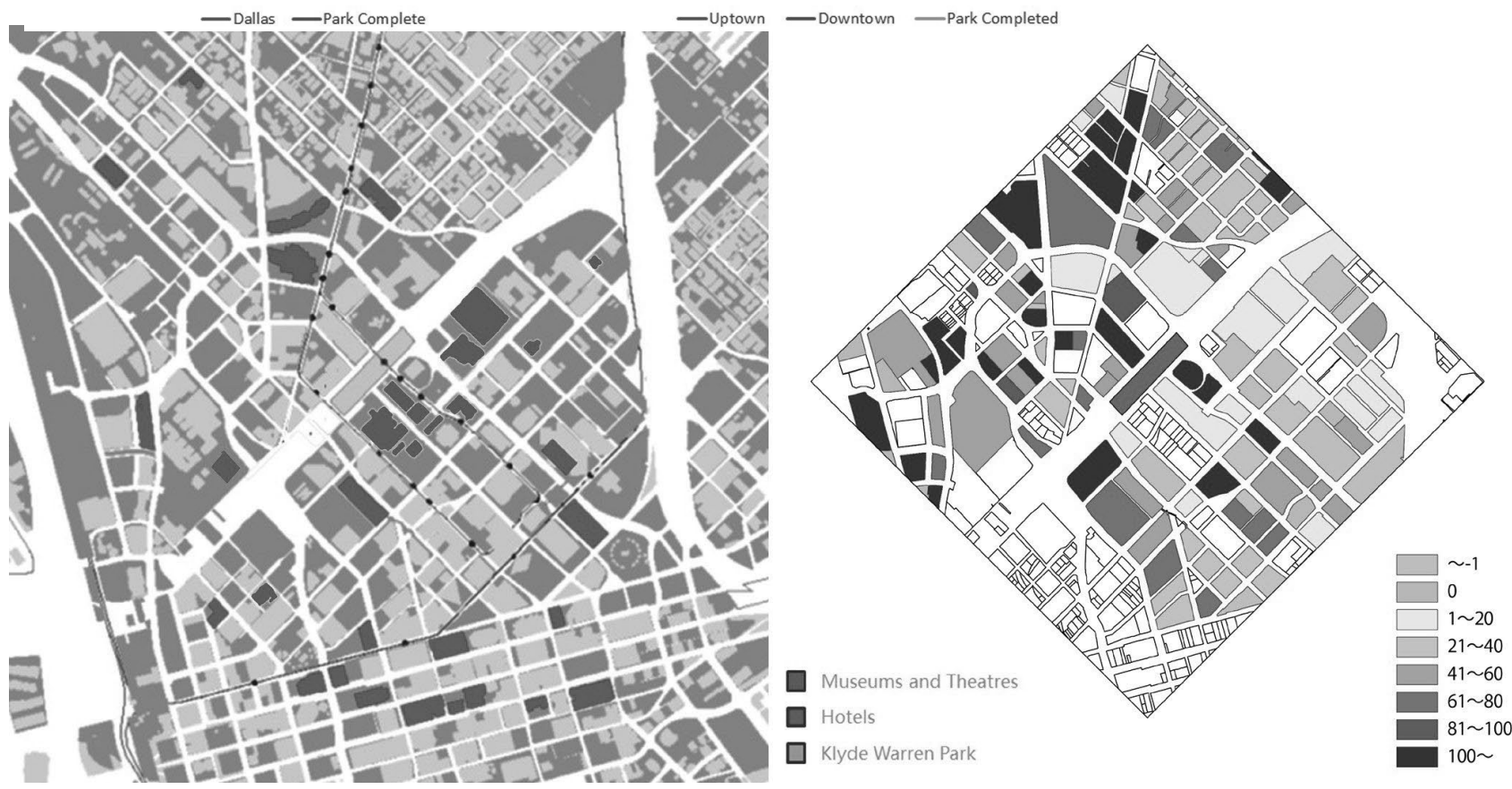
The data collected allows us to see how large of a population there is in order to accommodate it better. It is evident that the population increased greatly after the completion of Klyde Warren Park in 2012. The downtown and uptown populations rose due to the connectivity the park provided between the two areas. Klyde Warren Park has over 1 million visitors a year, in return, helping nearby urban businesses and residential areas. In recent years, Dallas' once large daytime population and scarce nighttime population is transforming into a "live-work-play community" because of the development of transformed buildings into mixed-use buildings. The people who live here are mostly professionals tired of commuting to work, families, or empty nesters who want to switch from a suburban lifestyle. Dallas has evolved into more of a pedestrian friendly environment, so some people don't have cars. Instead, they just walk or bike to their destinations. Klyde Warren Park encourages them to do so. A flood of investment is transforming old buildings into shiny mixed-use developments and drawing new shops, restaurants, and bars to the city center. Once a ghost town after $5 \mathrm{pm}$ on weekdays, downtown Dallas is becoming a live-work-play community all on its own.

\section{CONCLUSION}

Overall there is an increase of property value in the area along Klyde Warren Park by referencing the Dallas County Appraisal District's website. While the research attempting to determine if the market value increase is directly correlated to the creation of Klyde Warren Park was inconclusive, there is no denying development in the area has certainly increased. This can be due to a number of factors but ever since the fiscal end of 2012 there has been a massive increase in real estate in the Dallas area. This has helped increase development and redevelopment in the downtown and uptown area which in turn normally increases the market values.

For Uptown Dallas, the functions of the buildings in the area are mainly those of residences and retail, with a few larger office buildings. Uptown has a much higher volume of residences and retail than downtown does. This verifies that uptown is more often visited than downtown for extracurricular reasons. Whereas, downtown is mainly office buildings, concluding that majority of the visitors to this area are there for business purposes. This analysis of the building's opening year has shown that both uptown and downtown were built primarily before the construction and completion of Klyde Warren Park. Some buildings were constructed after, mainly the areas directly surrounding the park, but most were constructed well before the park. However, the park has shown to possibly influence buildings to change and renovate since its completion. Both division of Dallas have also grown immensely more populated and busy since the parks openings.

Klyde Warren Park has greatly helped the population in Dallas grow and thrive. In order to design a building or structure that will flourish in this environment, it is important to understand the population information. Due to the large population in the Dallas area, the building or structure will need to accommodate this as well as the lifestyles of the population. The age range, lifestyle, and amount of people will help customize this design to enhance the Dallas area as well as serve it.

In conclusion, this paper discusses how the economic impact spreads from the location of the park to the surrounding neighborhood, by the analysis of amount of visitors to the districts and increases of property values. And those impact will be visualized on the urban map.

\section{ACKNOWLEDGEMENTS}

I take this opportunity to express gratitude to who involved with this Klyde Warren Park research, all of the related people for the project: ARCH 406 students at the Department of Architecture, Texas A\&M University, Ms. Tara Green, President, Klyde Warren Park, Mr. Michael Gaffney, Senior Vice President of Operations, Klyde Warren Park, Mr. Nathan Elliott, Principal of OJB Landscape Architecture, Mr. Phil Puckett, Vice Chairman, CBRE, Mr. John Reynolds, Dallas City Hall for their help and support.

\section{ENDNOTES}

1. http://www.bcworkshop.org/posts/dallas-city-grids

2. http://www.uptowndallas.net

3. https://www.zillow.com/dallas-tx/Uptown-Dallas_att/

4. https://www.census.gov/programs-surveys/popest.html

5. https://www.census.gov/content/dam/Census/library/working-papers/2015/ demo/2015-Laughlin-01-Poster.pdf

6. https://dallasinnovates.com/ park-effect-how-klyde-warren-park-altered-face-downtown/

7. http://neighborhoods.dmagazine.com/dallas/central-dallas/downtown/ 